\title{
Musculoskeletal Disorder of Workers During Work From Home on Covid-19 Pandemic: A Descriptive Study
}

\author{
Condrowati ${ }^{1 *}$, Farahdina Bachtiar, Fandita T. Maharani ${ }^{2}$, Dyah Utari ${ }^{2}$ \\ ${ }^{1}$ Physiotherapy Program, Faculty of Health Science, Universitas Pembangunan Nasional Veteran Jakarta, Jakarta \\ ${ }^{2}$ Public Health Program, Faculty of Health Science, Universitas Pembangunan Nasional Veteran Jakarta, Jakarta \\ "Corresponding author.Email: condrowati@upnvj.ac.id
}

\begin{abstract}
Background: Musculoskeletal disorder is one of the health problems which can be caused by the workforce. Work-related to musculoskeletal disorder signed by general chronic pain. Due to the impact of Covid-19, the change of the work from the office to be work from home is worried to trigger musculoskeletal disorders. The aim is to identify musculoskeletal disorder of the workers during work from home on the Covid-19 pandemic. Method: One hundred and four Indonesian respondents participated in the research. The research location was in Indonesia. The method was a descriptive study. The measurement was the Nordic Musculoskeletal Questionnaire to investigate the musculoskeletal disorders of the workers. Result: The results showed that the workers $86.3 \%$ of the workers experienced musculoskeletal disorders during the last 12 months, while $66.3 \%$ of the workers experienced the problem during work from home. Furthermore, the proportion of the workers who had the problem in daily activity was $40 \%$, then $12.6 \%$ of the workers visit the doctor because of musculoskeletal disorders. Conclusion: The fourth highest regions of the body that experienced musculoskeletal disorders during work from home were the neck, shoulder, lower back, and upper back.
\end{abstract}

Keywords: musculoskeletal disorder, worker, COVID-19, work from home, Nordic Musculoskeletal Questionnaire

\section{INTRODUCTION}

Musculoskeletal disorder is one of the health problems which can be caused by the workforce. Work-related to musculoskeletal disorders signed by general chronic pain [1][2][3][4]. Based on the epidemiological study, an occupational factor potentially increased the risk of musculoskeletal disorders. Physical workload or force, repetitiveness, awkward posture, and seniority at the workplace were the most frequent factors which were found in the studies. The factors are statistically significantly more than $50 \%$ triggered the musculoskeletal disorder of neck, shoulder, and back region [5].

Regarding the musculoskeletal study, Phedy and Gatam (2016) collected the Nordic Musculoskeletal Questionnaire from the 241 dentists. The results revealed that $63.1 \%$ of the workers had the musculoskeletal disorder in which $36.5 \%$ was the fatigue, $24.9 \%$ was the muscle pain (neck, upper back, and lower back) [6]. The results are also supported by Celik et al (2018). The study was conducted with 528 office workers to determine musculoskeletal disorders and the factors that caused the problems. The researchers used the questionnaire which divided into several questions, like demographic data, whether the workers took exercise, the length of the time sat or stood, the number of the breaks, whether they faced the heavy lifting while working, stress level, the position of the body, and type of the chair. The results identified that the workers experienced the problem in the lower back with $55.1 \%$, neck with $52.5 \%$, and upper back with $53 \%$. Besides, the results revealed that sitting at the desk for a long time, the chair only supported the lumbar and the arms, the distance between mouse and keyboard little bit far, the head inclined at $45^{\circ}$ when working, not doing theexercise in daily life, and stress in the workplace become the factors which triggered musculoskeletal disorders [7].

At the end of 2019, the first case that was caused by the coronavirus disease (Covid-19) detected in the Wuhan, China, and then spread around the world, included Indonesia [8]. Indonesia is one of the countries which have to face and tackle the health pandemic in which the spread of the virus is through human to human rapidly and easily if the people are in contact with the infected. The pandemic makes people do physical distancing to prevent the spread. The government policy set that the societies are required to work from home, study from home, and also pray from home. 
The change of the work from the office to be work from home is worried to trigger musculoskeletal disorders. For example, the people who usually work from office have the chair which has set based on the ergonomic standard. When they have to work from home, the people usually sit on the chair which they have in the home, so that it does not appropriate with the ergonomic standard so that musculoskeletal disorder is possible experienced by the workers. Therefore, the study identified musculoskeletal disorder of the workers in Indonesia during work from home on the Covid-19 pandemic.

\section{METHOD}

In the study, we included all the workers who were work from home in Indonesia from March to July 2020 on the Covid-19 pandemic. According to the criteria, 104 workers fulfilled the questionnaire in the Google form. All the workers were Indonesian. The inclusion criteria were the workers who worked from home and not to be patients in the hospital or clinic. The exclusion criteria were health workers in the health service and not want to be a respondent in the study.

The study is a descriptive study using a questionnaire to collect the data. The questionnaire is a Nordic Musculoskeletal Questionnaire in which the aim is to investigate the musculoskeletal disorders of the workers. Table 1 showed the questions. The analysis data used SPSS.

Table 1. Questions used in the survey based on the Nordic Musculoskeletal Questionnaire

\begin{tabular}{|l|l|c|}
\hline No. & \multicolumn{1}{|c|}{ Descriptions } & Possible Answer \\
\hline 1. & Do you feel musculoskeletal disorders like pain or cramps in the last 12 months? & Yes/No \\
\hline 2. & Related to the previous question, which area do you feel the pain and cramps? & Choice \\
\hline 3. & Does the disorder give the impact on daily life activities? & Yes/No \\
\hline 4. & $\begin{array}{l}\text { Related to the previous question, which are the areas in the body that have the } \\
\text { problem? }\end{array}$ & Choice \\
\hline 5. & Do you see the doctor to tackle the problem? & Yes/No \\
\hline 6. & $\begin{array}{l}\text { Related to the previous question, which are the areas in the body that have the } \\
\text { problem? }\end{array}$ & Choice \\
\hline 7. & Do you feel musculoskeletal disorder in the last 7 days? & Yes/No \\
\hline 8. & $\begin{array}{l}\text { Related to the previous question, which are the areas in the body that have the } \\
\text { problem? }\end{array}$ & Choice \\
\hline
\end{tabular}

\section{RESULT}

As indicated above, the researchers were successfulin collecting 103 responses which have filled by the workers; only 95 fulfilled the research criteria. There are eight questions of the questionnaire in which all the workers gave the answers to all the questions.

Table 2 illustrated the detail of demographic information of all workers, including age, gender, profession, and the weeks of work from home. Based on the distribution, the highest age group of the workers is between 20 to 30 years old $(70.5 \%)$, followed by the age of 31 to 40 years old $(18.5 \%)$. Furthermore, the female workers are more than the male workers at $63.2 \%$ and $36.8 \%$, respectively. For the profession, the workers are divided into a different kind of professions in which the most frequency is company employee at $35.7 \%$, the second is academics at $29.4 \%$, followed by a government employee at $20 \%$, and the teacher, state-owned enterprise, entrepreneur, student at $15 \%$ after accumulation. Furthermore, related to the work from home, the respondents have worked from home on 9 to 12 weeks at $60 \%$.

Table 1. Demographic information of therespondents

\begin{tabular}{|l|c|c|}
\hline \multicolumn{1}{|c|}{ Characteristics } & $\begin{array}{c}\text { Frequency } \\
\text { (n) }\end{array}$ & $\begin{array}{c}\text { Percentage } \\
(\%)\end{array}$ \\
\hline Age & 67 & 70.5 \\
\hline $20-30$ & 18 & 18.9 \\
\hline $31-40$ & 7 & 7.4 \\
\hline $41-50$ & 3 & 3.2 \\
\hline $51-60$ & 35 & 36.8 \\
\hline Gender & 60 & 63.2 \\
\hline Male & 28 & 29.4 \\
\hline Female & 19 & 20 \\
\hline Profession & 33 & 35.7 \\
\hline Academics & 4 & 3.3 \\
\hline Government Employee & 2 & 2.1 \\
\hline Company Employee & 2 & 2.1 \\
\hline Teacher & \multicolumn{1}{|l}{} \\
\hline State-owned Enterprise & \multicolumn{1}{|l|}{} \\
\hline Entrepreneur & \multicolumn{2}{|l|}{} \\
\hline
\end{tabular}


Table 2. Musculoskeletal Disorder on the Last 12 Months

\begin{tabular}{|l|c|c|}
\hline $\begin{array}{l}\text { Work from home } \\
\text { (weeks) }\end{array}$ \\
\hline \hline $0-4$ & 9 & 9.5 \\
\hline $5-8$ & 23 & 24.2 \\
\hline $9-12$ & 57 & 60 \\
\hline $13-16$ & 3 & 3.2 \\
\hline $17-20$ & 2 & 2.1 \\
\hline $21-24$ & 1 & 1.0 \\
\hline & $\mathbf{9 5}$ & $\mathbf{1 0 0}$ \\
\hline
\end{tabular}

\subsection{The Proportion of Symptomatic Workers for Body} Region on the Last 12 Months

The frequency of the workers who experienced musculoskeletal disorders is shown in Table 3 . The results revealed that $86.3 \%$ of the workers have musculoskeletal disorders in the body region.

\begin{tabular}{|c|c|c|}
\hline $\begin{array}{c}\text { Musculoskeletal } \\
\text { Disorder }\end{array}$ & Frequency (n) & $\begin{array}{c}\text { Percentage } \\
(\boldsymbol{\%})\end{array}$ \\
\hline Yes & 82 & 86.3 \\
\hline No & 13 & 13.7 \\
\hline
\end{tabular}

The proportion of symptomatic workers for the body region in the last 12 months was revealed in Figure 1. The results showed that the neck is the most problem which is experienced by the worker with the percentage at $52 \%$, then followed bylower back at $45.3 \%$, shoulder at $41 \%$, and upper back at $39 \%$.

Figure 1. The proportion of musculoskeletal disorder of the workers on the Last 12 Months

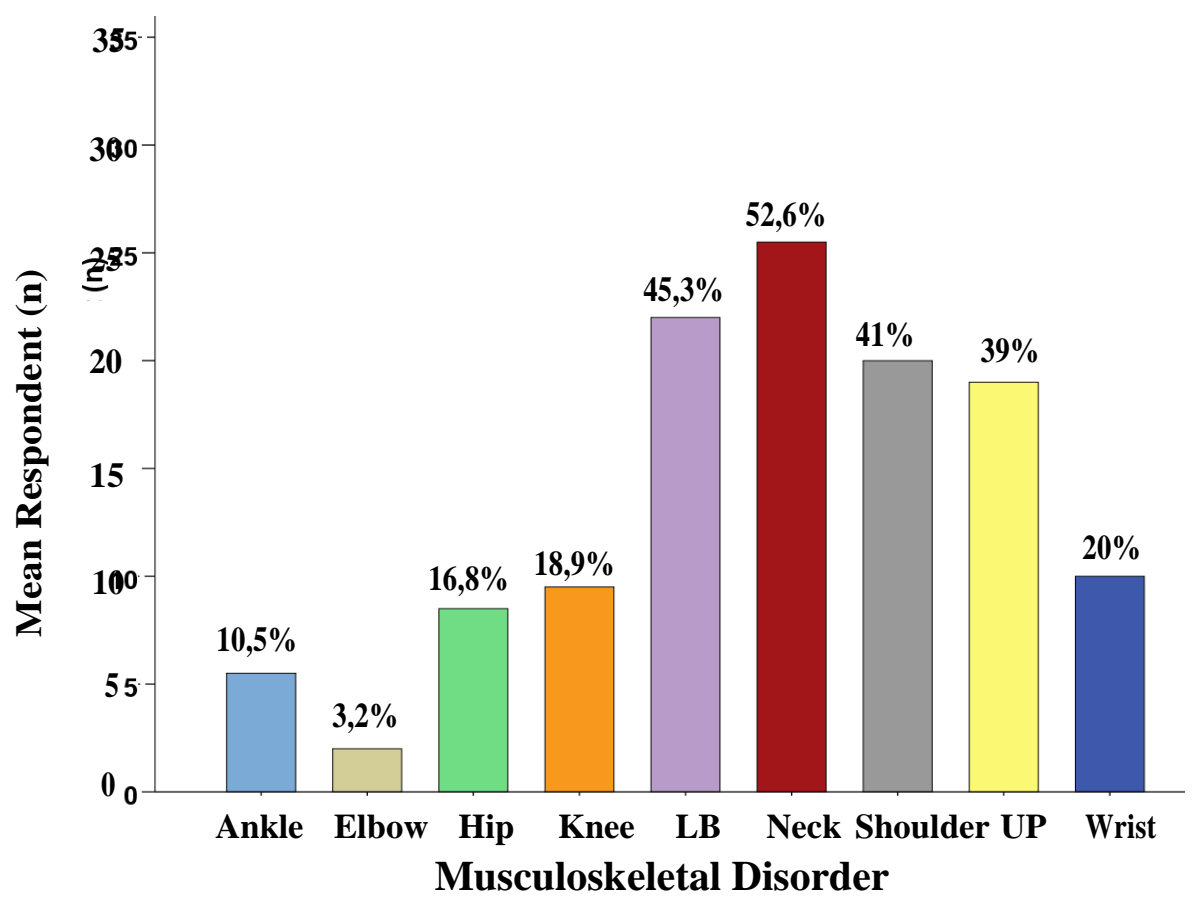

*LB: Lower Back *UP: Upper Back 
In Table 3, the workers who were disturbed in the daily activities because of musculoskeletal disorders were $40 \%$ of all workers, then $60 \%$ of workers did not have the problem during daily activities in the last 12 months.

Table 3. The frequency of workers disturbed in daily activities on the last 12 months

\begin{tabular}{|l|c|c|}
\hline $\begin{array}{c}\text { Musculoskeletal } \\
\text { Problem }\end{array}$ & $\begin{array}{c}\text { Frequency } \\
(\mathbf{n})\end{array}$ & $\begin{array}{c}\text { Percentage } \\
(\mathbf{\%})\end{array}$ \\
\hline Yes & $\underline{38}$ & $\underline{40}$ \\
\hline No & $\underline{57}$ & $\underline{60}$ \\
\hline
\end{tabular}

Based on Figure 2A, the most proportion of the workers who had the problem during daily activities in the body region was neck with the percentage at $55.3 \%$. Then it was followed by shoulder, upper back, and lower back with the percentage at $44.7 \%$, followed by the wrist at $23.9 \%$. Hip/thigh and ankle almost had the same proportion at $15.8 \%$ and $13.1 \%$, respectively. The lowest proportion of the problem was in the knee at $7.9 \%$ and elbow at $5.3 \%$.

In Figure 2B, the results revealed that $52.6 \%$ of the workers did not have a problem in daily activities related to the musculoskeletal problem. The results also showed that although the musculoskeletal disorder did not influence their activities, the workers still feel the problem. It can see that the neck region took the first proportion of the musculoskeletal problem of the workers, followed by shoulder, lower back, knee, upper back, wrist, ankle, and hip/thigh.

Figure 2. The proportion of symptomatic workers disturbed in the daily activities

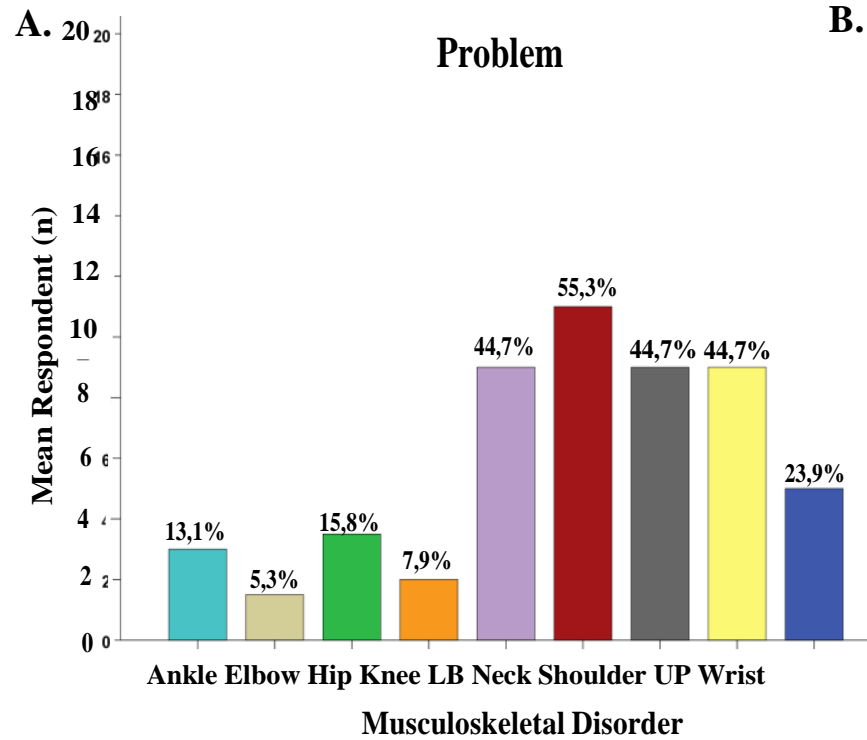

*LB: Lower Back

*UP: Upper Back

*NP: No Problem

\subsection{The Proportion of workers visit the doctor due to a musculoskeletal disorder in the last 12 months}

In Table 4, the workers visit the doctor in the last 12 months caused by musculoskeletal disorder $12,6 \%$ otherwise, the workers did not see the doctors at $87.3 \%$.

Table 4. The proportion of the workers visit the doctor due to musculoskeletal disorder

\begin{tabular}{lcc}
\hline $\begin{array}{c}\text { Musculoskeletal } \\
\text { Problem }\end{array}$ & $\begin{array}{c}\text { Frequency } \\
\text { (n) }\end{array}$ & $\begin{array}{c}\text { Percentage } \\
(\boldsymbol{\%})\end{array}$ \\
\hline Yes & 12 & $12,6 \%$ \\
\hline No & 83 & $87,3 \%$ \\
\hline
\end{tabular}

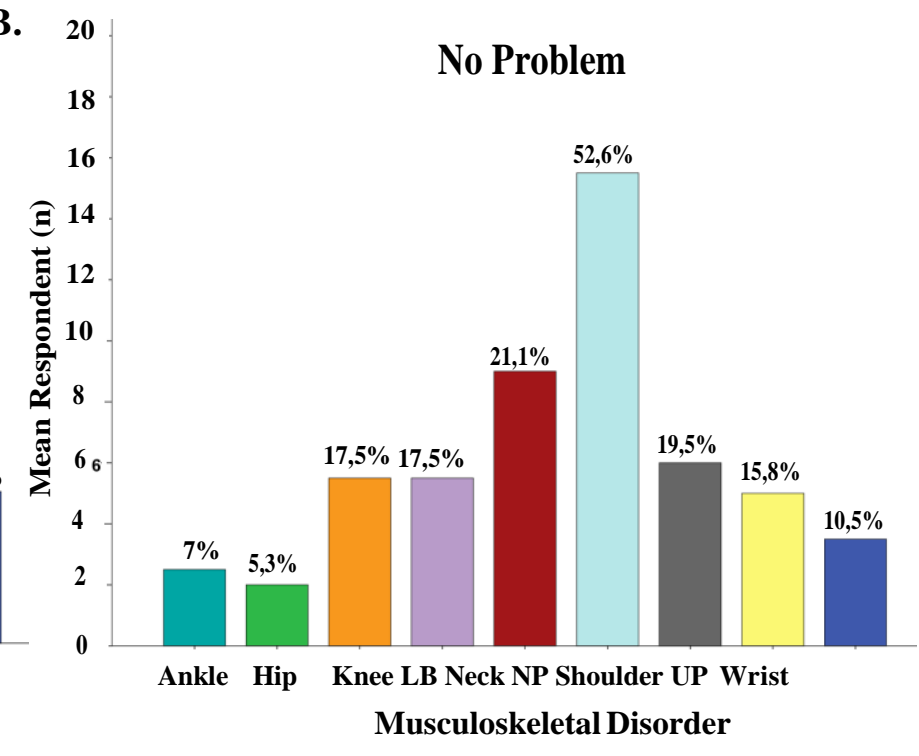

Figure 3A illustrated the proportion of the workers visit the doctor because of the musculoskeletal disorder. The results showed that the workers had the problem in the neck and lower back that become the most problem them to check the doctor with the percentage at $25 \%$. Besides, shoulder, 
upper back, and wrist were in the second position that caused the workers to see the doctor with the percentage at $16.6 \%$, followed by hip/thigh and ankle at $8.3 \%$.

In Figure 3B, although, the workers did not see the doctor, they still experienced musculoskeletal disorders, but it might be in their tolerance. The results revealed that $38.5 \%$ of the workers did not feel the problem, while other workers still felt the problem in most third problem the neck, such as the neck, upper back, and lower back.

Figure 3. The proportion of the workers visit and did not see the doctor due to musculoskeletal disorder

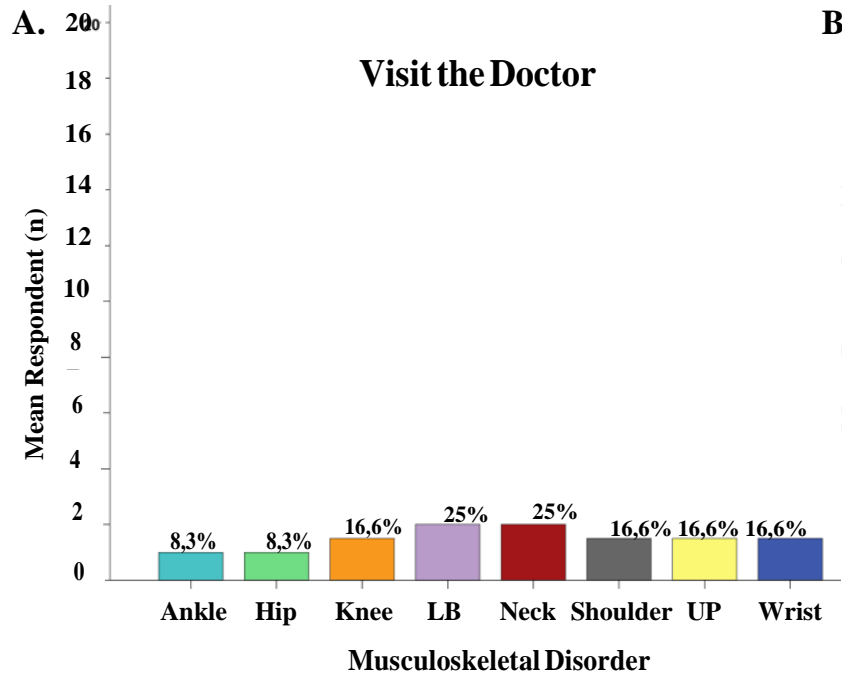

*LB: Lower Back

*UP: Upper Back

*NP: No Problem

\subsection{The Proportion of Symptomatic Workers for Body Region on the Last 7 Days during Work from Home}

In Table 5, the workers who experienced musculoskeletal disorders work from home at $66.3 \%$. Then the others did not feel the problem in musculoskeletal during work from home at $33.7 \%$.

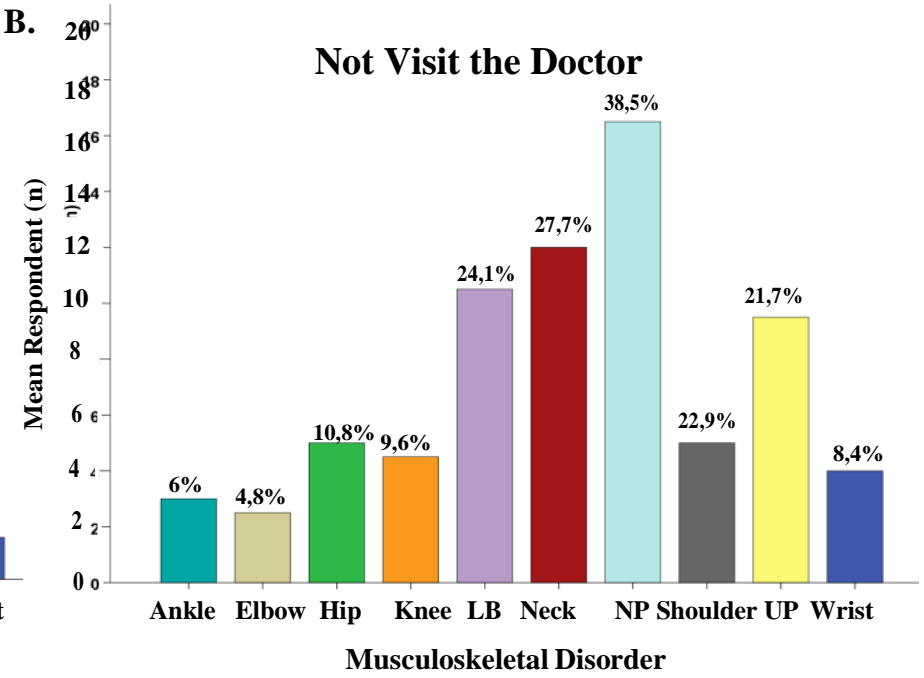

Table 5. Musculoskeletal disorder on the last seven days during work from home

\begin{tabular}{lcc}
\hline $\begin{array}{c}\text { Musculoskeletal } \\
\text { Problem }\end{array}$ & $\begin{array}{c}\text { Frequency } \\
\text { (n) }\end{array}$ & $\begin{array}{c}\text { Percentage } \\
(\boldsymbol{\%})\end{array}$ \\
\hline Yes & 63 & $66,3 \%$ \\
\hline No & 32 & $33,7 \%$ \\
\hline
\end{tabular}

In Figure 4, the results showed that the workers had musculoskeletal disorders during work from home. In detail, the region's body like the neck to be the most problem with a percentage at $54 \%$. Shoulder, lower back, and upper back were at $36.5 \%, 34.9 \%$, and $31.7 \%$, respectively. The workers had the problem in the ankle at $22.2 \%$. Furthermore, hip/thigh 
and knee had the same proportion at $17.4 \%$, followed by the wrist at $15.9 \%$ and elbow at $6.3 \%$.

Figure 4. The proportion of the musculoskeletal disorder of the workers during work from home

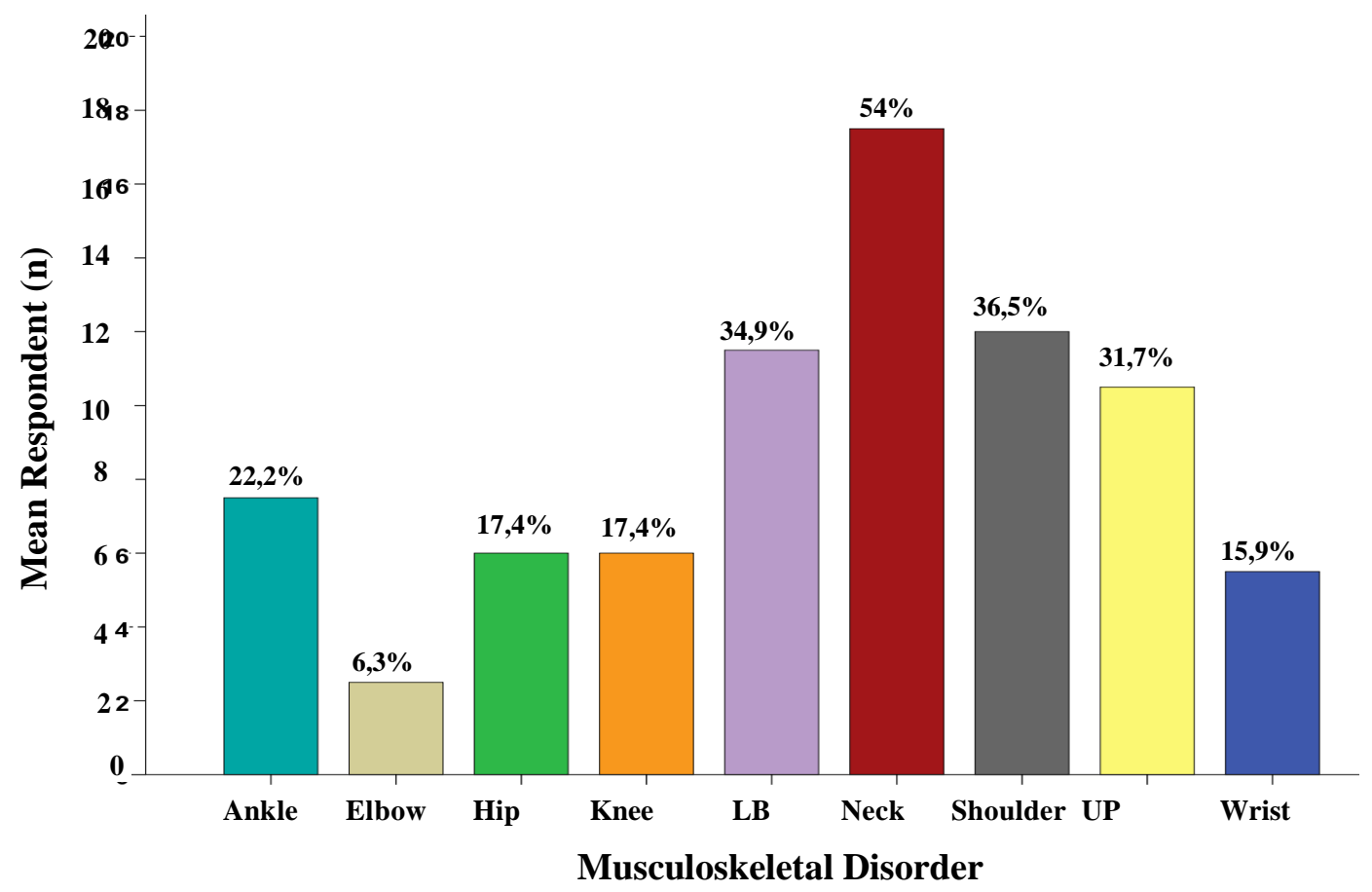

\section{DISCUSSION}

The current study examined the musculoskeletal disorder of workers during work from home on the Covid-19 pandemic. Overall, it is found that $86.3 \%$ of the workers experienced musculoskeletal disorders. The results showed that the fourth highest region of the body that experienced musculoskeletal disorder was the neck, shoulder, lower back, and upper back with ranges between $31 \%$ and $65 \%$. The results were confirmed by a systematic review that was presented by Erik and Smith (2011). The researchers suggested that the prevalence of musculoskeletal disorder ranges between $39 \%$ and $95 \%$ in which the most prevalent body sites to be the neck, back, and upper limbs [9][10][11].

Besides, the studies by Phedy and Gatam (2016), Azma et al. (2016), Chiu and Lam (2006), and Buckle and Devereux (2002) confirmed that neck pain, shoulder, upper back, and lower back were the most commonly affected region in the musculoskeletal disorder [6][12][13][14]. During working activities in front of the computer, the upper trapezius muscle was the most exerted muscle that leads to the generation of internal forces within the body in which it will increase the muscle tension and pain in the shoulder and neck. While the workers are working from home, the musculoskeletal disorder might be triggered because the workers have to work for five to seven hours a day, they will sit on a chair that they have in the home. Sometimes, they did not have the chair that is appropriate with the ergonomic standard. With this condition, when they often sat with the slumps forward, it will reduce the muscular effort that is required to maintain a seated position so that this position will cause the ligaments and muscles which support the spine happens the increasing the tension. The seated position is possible to cause the upper and lower back pain of the workers during work from home. It is supported by some studies that 
explained that the seated position is one of the factors which triggered musculoskeletal disorder [15][16][17].

Our data identified that $40 \%$ of the workers experienced the problem during the daily activity then $12.6 \%$ of the workers visit the doctor because of the musculoskeletal disorder in which the highest regions are neck and lower back. The results are supported by Beaton (2002) that reported that $29 \%$ of the workers had seen the health care practitioner[18]. That is because the prolonged static contraction of the skeletal muscles of the back causes impairment of the blood flow to the muscles (ischemia), together with edema, and accumulation of the waste metabolism in which it will trigger the pain spasm.

The results also showed that the proportion of the workers experienced musculoskeletal disorders in the last 12 months is higher than during work from home. There may be other factors that cause musculoskeletal disorders such as psychosocial and individual factors. However, in the study, we did not ask the workers what the cause of the disorder is. The study by Feng et al. (2016) suggested that lack of work breaks, working under pressure, and lack of social support lead directly to the stress in which the stress can increase muscle tension that develops the musculoskeletal disorder. Then, individual factor like injury also causes musculoskeletal disorders [17].

The study had several limitations. Firstly, the sample size of the study might be insufficient due to the limited time of collecting data. Secondly, we used a Nordic Musculoskeletal Questionnaire as a self-reported questionnaire to identify musculoskeletal disorders; the study might be prone to recall bias since the respondents probably do not remember their entire problem on the last 12 months. Nevertheless, a Nordic Musculoskeletal Questionnaire is commonly a questionnaire which is used and proved to be valid for assessing musculoskeletal disorder [19][20]. Future studies should include the larger sample and a longer period of the time to further identify musculoskeletal disorders of Indonesian workers during the Covid-19 pandemic.

\section{CONCLUSION}

The results suggested that the workers $86.3 \%$ of the workers experienced musculoskeletal disorders during the last 12 months, while $66.3 \%$ of the workers experienced the problem during work from home. Furthermore, the proportion of the workers who had the problem in the daily activity was
$40 \%$, then $12.6 \%$ of the workers visit the doctor because of musculoskeletal disorder. The fourth highest region of the body that experienced musculoskeletal disorder was the neck, shoulder, lower back, and upper back.

\section{REFERENCES}

[1] A. Choobineh, S. H. Tabatabaei, A. Mokhtarzadeh, and M. Salehi, "Musculoskeletal problems among workers of an Iranian rubber factory," J. Occup. Health, vol. 49, no. 5, pp. 418-423, 2007.

[2] H. Harcombe, G. P. Herbison, D. McBride, and S. Derrett, "Musculoskeletal disorders among nurses compared with two other occupational groups," Occup. Med. (Lond)., vol. 64, no. 8, pp. 601-607, 2014.

[3] V. Occhionero, L. Korpinen, and F. Gobba, "Upper limb musculoskeletal disorders in healthcare personnel," Ergonomics, vol. 57, no. 8, pp. 1166-1191, 2014.

[4] H. Harcombe, D. McBride, S. Derrett, and A. Gray, "Prevalence and impact of musculoskeletal disorders in New Zealand nurses, postal workers and office workers," Aust. N. Z. J. Public Health, vol. 33, no. 5, pp. 437-441, 2009.

[5] J. Malchaire, N. Cock, and S. Vergracht, "Review of the factors associated with musculoskeletal problems in epidemiological studies," Int. Arch. Occup. Environ. Health, vol. 74, no. 2, pp. 79-90, 2001.

[6] P. Phedy and L. Gatam, "Prevalence and associated factors of musculoskeletal disorders among young dentists in Indonesia," Malaysian Orthop. J., vol. 10, no. 2, pp. 1-5, 2016.

[7] S. Celik, K. Celik, E. Dirimese, N. Tasdemir, T. Arik, and İb. Büyükkara, "Determination of pain in musculoskeletal system reported by office workers and the pain risk factors," Int. J. Occup. Med. Environ. Health, vol. 31, no. 1, pp. 91-111, 2018.

[8] G. Li et al., "Coronavirus infections and immune responses," J. Med. Virol., vol. 92, no. 4, pp. 424432, 2020.

[9] P. N. Erick and D. R. Smith, "A systematic review of musculoskeletal disorders among school teachers," BMC Musculoskelet. Disord., vol. 12, no. 1, p. 260, 2011.

[10] F. Rahimi, K. Kazemi, S. Zahednejad, D. LópezLópez, and C. Calvo-Lobo, "Prevalence of WorkRelated Musculoskeletal Disorders in Iranian 
Physical Therapists: A Cross-sectional Study," J. Manipulative Physiol. Ther., vol. 41, no. 6, pp. 503-507, 2018.

[11] M. Valipour Noroozi, M. Hajibabaei, A. Saki, and Z. Memari, "Prevalence of Musculoskeletal Disorders Among Office Workers," Jundishapur J. Heal. Sci., vol. 7, no. 1, pp. 1-5, 2015.

[12] R. Nur Azma BA, "Work Related Musculoskeletal Disorders in Female Nursing Personnel: Prevalence and Impact," Int. J. Collab. Res. Intern. Med. Public Heal., vol. 2016, no. August, 2016.

[13] T. T. W. Chiu and P. K. W. Lam, "The prevalence of and risk factors for neck pain and upper limb pain among secondary school teachers in Hong Kong," J. Occup. Rehabil., vol. 17, no. 1, pp. 19-32, 2007.

[14] P. W. Buckle and J. J. Devereux, "The nature of work-related neck and upper limb musculoskeletal disorders," vol. 33, pp. 207-217, 2002.

[15] J. B. Carter and E. W. Banister, "Musculoskeletal problems in VDT work: a review," no. January 2015, pp. 37-41, 2007.

[16] H. Dong, Q. Zhang, G. Liu, T. Shao, and Y. Xu, "Prevalence and associated factors of musculoskeletal disorders among Chinese healthcare professionals working in tertiary hospitals: A cross-sectional study," BMC Musculoskelet. Disord., vol. 20, no. 1, pp. 1-7, 2019.

[17] Q. Feng, S. Liu, L. Yang, M. Xie, and Q. Zhang, "The prevalence of and risk factors associated with musculoskeletal disorders among sonographers in central China: A cross-sectional study," PLoS One, vol. 11, no. 10, pp. 1-18, 2016.

[18] D. E. Beaton, D. C. Cole, M. Manno, C. Bombardier, S. Hogg-Johnson, and H. S. Shannon, "Describing the burden of upperextremity musculoskeletal disorders in newspaper workers: What difference do case definitions make?," J. Occup. Rehabil., vol. 10, no. 1, pp. $39-53,2000$.

[19] J. O. Crawford, "The Nordic Musculoskeletal Questionnaire," Occup. Med. (Chic. Ill)., vol. 57, no. 4, pp. 300-301, 2007.

[20] I. M. Ramdan, K. Duma, and D. L. Setyowati, "Reliability and Validity Test of the Indonesian Version of the Nordic Musculoskeletal Questionnaire (NMQ) to Measure
Musculoskeletal Disorders (MSD) in Traditional Women Weavers," Glob. Med. Heal. Commun., vol. 7, no. 2, pp. 123-130, 2019. 